\title{
A TRANSPARÊNCIA PÚBLICA NOS MUNICÍPIOS INTEGRANTES DO COREDE/MISSÕES-RS E SUA RELAÇÃO COM OS INDICADORES SOCIOECONÔMICOS
}

\author{
PUBLIC TRANSPARENCY IN THE MUNICIPALITIES OF COREDE/MISSÕES-RS AND \\ ITS RELATIONSHIP WITH THE SOCIOECONOMIC INDICATORS
}

\author{
Laura Luiza Mallmann Franke \\ Universidade Federal da Fronteira Sul, RS, Brasil \\ E-mail: lauraluizafranke@gmail.com \\ Monize Sâmara Visentini \\ Universidade Federal da Fronteira Sul, RS, Brasil \\ E-mail: monize.visentini@uffs.edu.br \\ Ari Söthe \\ Universidade Federal da Fronteira Sul, RS, Brasil \\ E-mail: ari.sothe@uffs.edu.br \\ Micheli dos Santos \\ Universidade Federal da Fronteira Sul, RS, Brasil \\ E-mail: micheli.santos@uffs.edu.br
}

Recebido em: 31.05.2020 - Aceito em: 29.06.20

DOI: http://dx.doi.org/10.5902/2526629242806

RESUMO: Este trabalho objetiva mensurar o nível de transparência, por meio da Escala Brasil Transparente (EBT), nos portais eletrônicos das prefeituras que fazem parte do COREDE Missões-RS, bem como a relação de transparência com os indicadores socioeconômicos. Os resultados apresentam a composição de um ranking, sendo que nos primeiros lugares estão os municípios de Cerro Largo, de Santo Antônio das Missões e de São Paulo das Missões, pelo fato de atenderem a todas as prerrogativas solicitadas. Também se observou a relação significativa, de efeito médio e positivo, entre o nível de transparência e os indicadores população e receita total arrecadada. Por fim, percebeu-se que os municípios investigados apresentam baixos níveis de transparência eletrônica, principalmente no que se refere à transparência passiva.

Palavras-chave: Portais eletrônicos;Administração Pública; Transparência Pública.

ABSTRACT: This paper aims to measure the level of transparency, through the Brazilian Transparent Scale (EBT), in the electronic portals of the municipalities belonging to COREDE Missões-RS, as well as the relationship of transparency with socioeconomic indicators. Results present the composition of a ranking, being 
the municipalities of Cerro Largo, Santo Antônio das Missões and São Paulo das Missões the first places, due to the fact that they meet all prerogatives requested. It was also observed a significant relationship, with medium and positive effect, between the level of transparency and the population and total revenue. Conclusively, it was observed that investigated municipalities have low levels of electronic transparency, especially in the case of passive transparency.

Keywords: Electronic Portals; Public Administration; Public Transparency.

\section{INTRODUÇÃO}

A transparência na gestão pública vem sendo apontada como um fator relevante para uma melhor qualidade das políticas públicas, do combate à corrupção e do processo de prestação de contas pelo fato de fomentar a accountability que, de acordo com Cruz et al. (2012), significa responsabilidade de prestar contas.

No âmbito nacional e internacional, a transparência dos governos tem sido requerida tanto pela sociedade como pelos órgãos fiscalizadores devido às assimetrias informacionais existentes que facilitam a adoção de práticas contrárias à gestão pelos interesses da sociedade. No Brasil, a transparência nas contas da gestão pública e na evidenciação dos atos ganhou maior notoriedade a partir da Lei de Responsabilidade Fiscal (LRF), também chamada de Lei Complementar $\mathrm{n}^{\circ}$ 101/2000 (Cruz et al., 2012).

Apesar de a LRF ter sido publicada somente no ano de 2000, na Constituição Federal de 1988 (Brasil, 1988) já estavam previstos, no artigo 37, alguns princípios que a Administração Pública deveria obedecer, como: legalidade, impessoalidade, moralidade, publicidade e eficiência. A aprovação da LRF fortaleceu o princípio da publicidade, estabelecendo normas voltadas para a responsabilidade na gestão fiscal para que houvesse um maior controle das finanças públicas (Brocco et al., 2018).

A Lei Complementar n`131/2009, também conhecida como Lei da Transparência, acrescentou dispositivos à LRF a fim de determinar que a disponibilização de informações sobre a execução orçamentária e financeira da União, dos Estados, do Distrito Federal e dos Municípios seja em tempo real (Brasil, 2009). Para corroborar a busca pela transparência na gestão pública, em 2011 foi criada a Lei 12.527, mais conhecida como Lei de Acesso à Informação (LAI), que tem como finalidade garantir ao cidadão o direito constitucional, ao mesmo tempo que impõe a todas as unidades federativas a responsabilidade pelo seu cumprimento. Além disso, essa legislação obriga, também, o cumprimento da transparência ativa e da 
transparência passiva (Santos, 2017).

Devido à necessidade de se ter conhecimento sobre a transparência na gestão pública, o objetivo deste trabalho é mensurar o nível de transparência, por meio da Escala Brasil Transparente (EBT), nos portais eletrônicos das prefeituras que fazem parte do Conselho Regional de Desenvolvimento das Missões/RS e avaliar a relação desses portais com os seguintes indicadores socioeconômicos: população, receita total arrecadada, PIB per capita, Índice de Desenvolvimento Humano Municipal (IDH-M), taxa de alfabetização e Índice Firjan de Desenvolvimento Municipal (IFDM).

Ressalta-se que a EBT foi criada pela Controladoria Geral da União (CGU), em 2015, para atender às competências tanto da LRF quanto da LAI. Esta escala mede a transparência pública através da avaliação do grau de cumprimento de dispositivos da Lei de Acesso à Informação (Brasil, 2017).

Também, destaca-se que o COREDE Missões/RS foi escolhido como objeto de estudo pelo fato de que a maioria das pesquisas realizadas semelhantes a esta (Silva, Kumegawa \& Vasconcelos, 2016; Bernardo, Reis \& Sediyama, 2017; Brocco et al., 2018) preocuparam-se em avaliar municípios brasileiros de grande porte, não fazendo alusão aos municípios pequenos, como é o caso dos integrantes do COREDE Missões/RS. Logo, a importância de estudar municípios de pequeno porte se dá pelo fato de que representam $90 \%$ das cidades brasileiras e a realidade socioeconômica e cultural encontrada é distinta quando comparada a grandes centros (De Oliveira \& Santos, 2017).

De acordo com o estudo realizado por Bertê et al. (2015), entre os anos de 2000 a 2010, o COREDE Missões/RS foi aquele que apresentou maior taxa de perda populacional, sendo a maior parte na área rural. A partir dessa discussão, surge o interesse neste trabalho, pois a falta de transparência nos atos administrativos pode levar à alienação da sociedade em relação à gestão pública. Por isso, promover ações e estimular o aumento no nível de transparência dos atos governamentais criam condições para a participação da sociedade nas medidas de controle social (Cruz et al., 2012).

\section{REFERENCIAL TEÓRICO}

A preocupação com a transparência na gestão pública no Brasil, segundo Cruz, Silva e Santos (2010), ganhou notoriedade na década de 1990, logo após a abertura política, pois as reformas pelas quais o país passou trouxeram discussões em relação às contas públicas, resultando na aprovação da Lei de Respon- 
sabilidade Fiscal (LRF) ou Lei Complementar n 101/2000 (Brasil, 2000). Desde então, normativos legais como a Lei Complementar n 131/2009 ou Lei da Transparência, que visa a disponibilização de informações públicas sobre a receita, as despesas, os salários dos servidores públicos e outros nos portais eletrônicos, juntamente com a Lei de Acesso à Informação (LAI) ou Lei ${ }^{\circ} 12.527$, que decreta o direito do cidadão ao acesso às informações públicas, trouxeram um novo rumo na relação existente entre cidadão e gestor público, pois tornaram obrigatória a divulgação das informações (Bairral, Silva \& Alves, 2015).

A transparência das ações das gestões públicas está sendo vista como uma forma de diminuir a assimetria de informações, dando espaço para uma cultura de abertura de dados e informações e deixando para trás, mesmo que lentamente, a cultura do segredo (Silva et al., 2019). De acordo com Tejedo-Romero e Araujo (2018), isso ocorre porque os cidadãos estão pressionando mais ativamente a administração pública, fazendo com que a gestão seja cada vez mais transparente.

Esse processo de maior divulgação das informações traz como resultado uma confiança maior dos cidadãos nas gestões municipais, além de uma melhor reputação como um governo ético, responsável e transparente (Tejedo-Romero \& Araujo, 2018). Muñoz, Bolívar e Hernández (2017) afirmam que a ampla divulgação de informações está ocorrendo graças às tecnologias de informação e comunicação (TICs), que possuem pilares fundamentais quando se trata de meIhorias na gestão pública e que visam, principalmente, melhorar a transparência e a confiança nas informações.

Contudo, ao analisar os municípios do COREDE Missões/RS para compreender as práticas dos gestores em relação à transparência, Santos e Visentini (2018) encontraram como resultados que a divulgação de informações da administração pública não está totalmente em conformidade com a legislação, além de haver resistência dos gestores em disponibilizar informações. Isso porque, quando cumprem com a legislação é para divulgar informações obrigatórias, e as demais passam por um "filtro" da gestão, impedindo a efetivação da LAl.

O interesse pela investigação acerca da transparência na gestão pública também se reflete no meio acadêmico, sendo que nos últimos anos, houve a publicação de uma série de investigações relacionando os níveis de transparência com indicadores socioeconômicos, motivo que levou ao emprego de tais indicadores neste trabalho.

A partir de um cenário de ausência de estudos anteriores que avaliassem esses indicadores, Cruz, Silva e Santos (2010) investigaram o nível de transparência fiscal eletrônica dos maiores municípios do Rio de Janeiro, bem como os 
fatores que possivelmente o influenciaram. Obteve-se como resultado que existe relação positiva e significativa entre o nível de transparência com as variáveis: população, receita orçamentária, taxa de alfabetização e IDH-M, sendo o PIB per capita pouco relevante quando relacionado com a transparência.

No estudo de Cruz et al. (2012), investigou-se o nível de transparência da gestão pública dos 100 maiores municípios brasileiros e quais os indicadores que contribuíram para tal nível de transparência. Para tanto, os autores construíram um modelo chamado ITGP-M ou Índice de Transparência da Gestão Pública Municipal. Como resultado, os autores afirmam que a associação geralmente ocorre na direção positiva entre os indicadores socioeconômicos PIB per capita, IDH-M, receita orçamentária, taxa de alfabetização e IFDM ${ }^{1}$ e os níveis de transparência das informações divulgadas pela gestão pública, "ou seja, melhores condições socioeconômicas tendem a implicar maior nível de transparência por parte dos municípios" (Cruz et al., 2012, p. 173).

Em adição, Ribeiro e Zuccolotto (2012) investigaram a transparência de 1.710 municípios selecionados em todo o território nacional e confirmaram que os municípios com maior eficiência em se tratando da arrecadação de receitas orçamentárias divulgam as informações em seus portais eletrônicos em maior quantidade. Logo, municípios com maior poder de gerar recursos tendem a ter uma maior capacidade de manter os sistemas de informação eletrônicos mais atualizados e eficientes.

Apesar disso, Michener, Moncau e Velasco (2015) afirmam que no Brasil ainda são encontrados problemas em relação às informações divulgadas pelo poder público, isto porque, muitas vezes, elas não são compreendidas por todos os cidadãos. Além disso, manter os sistemas de informação eletrônicos atualizados é uma grande dificuldade, visto que muitos órgãos públicos sequer possuem plataformas ou sistemas específicos de atendimento ao cidadão. Um exemplo disso, segundo os autores, é a falta de sistemas que recebam os pedidos de acesso à informação, o que leva muitos órgãos públicos a transferirem esta atribuição para as ouvidorias ou o Fale Conosco.

Considerando o Sul do Brasil, Machado (2013) procurou identificar os fatores explicativos do nível de transparência dos municípios mais populosos da região. Para isso, foram analisados os municípios com população superior a 50 mil habitantes e foi construído um grupo de 86 indicadores. O resultado obtido é que os fatores que indicam o nível de evidenciação dos municípios são: IFDM, receita corrente líquida e o partido político do prefeito municipal. Já os fatores que 
explicam o nível de evidenciação de informações obrigatórias são PIB per capita e IFDM, e os fatores que explicam as informações voluntárias são PIB per capita, população e IFDM.

A partir do atual cenário da transparência, Queiroz et al. (2013) identificaram que do total de 167 municípios do Rio Grande do Norte, somente 56 possuíam websites com informações disponíveis aos cidadãos. A pesquisa foi realizada através da construção de um índice de disclosure (divulgação das informações) desenvolvido por Avelino, Mário, Carvalho e Colauto (2011). Esse índice foi relacionado às seguintes variáveis: população, receita total arrecadada e IFDM. Os autores obtiveram como resultado que as variáveis população e receita total arrecadada evidenciaram uma relação fraca com o índice disclosure, e a variável IFDM possui relação moderada.

Diante da importância do cumprimento da LRF e da LAI, Marques (2014) analisou a evidenciação de indicadores exigidos por essas leis nas páginas eletrônicas das prefeituras dos municípios do Rio Grande do Sul com população entre 10 mil e 50 mil habitantes, contando, portanto, com um total de 122 municípios, sendo somente 94 analisados. Os dados obtidos revelaram que a população dos municípios influencia na maior ou menor evidenciação; que o montante da receita corrente líquida tem influência moderada positiva na divulgação; e que não há diferença nos níveis de divulgação de indicadores da LRF e da LAI em municípios com menor ou maior PIB per capita, IDH-M e taxa de analfabetismo.

Para evidenciar o nível de transparência municipal, a pesquisa de Avelino et al. (2014) teve como objetivo identificar as características que explicam o nível de transparência de 130 municípios de Minas Gerais, sendo 65 considerados de pequeno porte e 65 de médio e grande portes. Para tanto, os autores criaram o Índice de Disclosure Voluntário Municipal (IDV-M). As variáveis/indicadores estudados nessa pesquisa foram: gênero do gestor municipal, filiação partidária do prefeito, escolaridade do gestor municipal, PIB per capita, receita orçamentária, população e transferências de recursos da União, Índice de Desenvolvimento Humano Municipal (IDH-M), taxa de alfabetização, Índice Firjan de Desenvolvimento Municipal (IFDM), Índice Firjan de Gestão Fiscal (IFGF)² e participação no Programa de Fiscalização de Recursos Federais a partir de sorteios públicos. Como resultado, os autores identificaram que as variáveis que explicam o nível de disclosure voluntário são: população, receita orçamentária, transferências de recursos da União para os municípios, filiação partidária (PT, PMDB e PR) e IFDM.

Buscando identificar a transparência em estados, Rossoni e Beiruth (2016) realizaram um estudo para identificar quais das 78 prefeituras do estado do Espí- 
rito Santo são mais transparentes quando se trata de divulgar informações sobre a gestão pública municipal nos sítios eletrônicos e quais são as variáveis que explicam o nível de transparência. Tais variáveis foram: PIB per capita, população, IDH-M, receita orçamentária, IFDM e orientação político-partidária do prefeito. Como resposta, o estudo mostrou que há relação positiva entre os níveis de transparência e os indicadores: população, IFDM e a orientação político partidária do prefeito (esquerda).

Possamai e Schindler (2017) afirmam que em municípios maiores, cujo PIB per capita seja alto, juntamente com uma maior capacidade arrecadatória, o índice de transparência tem a tendência de ser mais expressivo, pois os municípios possuem maior capacidade autônoma para investir em sistemas de gestão da informação e de ferramentas de transparência na internet.

Abrangendo o estado de Minas Gerais, Bernardo, Reis e Sediyama (2017) realizaram um estudo em 66 municípios de médio e de grande porte. Para identificar quais os elementos que estão relacionados com o nível de transparência na administração pública, os autores construíram o Indicador de Transparência Municipal (ITM). Além disso, algumas variáveis como taxa de população urbana, taxa de emprego no setor formal, renda per capita, receita orçamentária, IFGF, taxa de alfabetização, índice de Gini e número de conselhos ativos foram analisadas. Os resultados apontaram que, quanto maior for a disponibilidade de recursos financeiros e taxa de alfabetização, maior é a predisposição da administração pública em ser transparente.

Estudando o estado do Rio Grande do sul, Brocco et al. (2018) constituíram uma amostra de 43 cidades com uma população acima de 50 mil habitantes. Os resultados indicaram que o único fator que teve relativa significância para explicar o nível de transparência dos municípios foi o Índice Firjan de Desenvolvimento Municipal.

A partir dos estudos apresentados, identificou-se que os indicadores mais utilizados (em 10 dos 12 estudos levantados) foram população, receita total arrecadada e PIB per capita. Entretanto, desses dez estudos levantados, apenas três tiveram relação entre PIB per capita e transparência; em compensação, as variáveis população e receita total arrecadada tiveram relação significativa com a transparência em 6 e em 8 estudos, respectivamente.

Já a taxa de alfabetização e o IFDM foram avaliados em metade dos estudos e, na maioria das vezes, foram significativos, mostrando, portanto, relação com a transparência. Além disso, foi analisada a relação entre transparência e IDH-M em cinco estudos, obtendo significância somente em dois. Por fim, o IFGF foi o indica- 
dor menos estudado e percebe-se que não teve relação com a transparência, não sendo replicada a sua relação nesta investigação. Todos os demais indicadores anteriormente mencionados (população, receita total arrecadada, PIB per capita, IDH-M, taxa de alfabetização, IFGF e IFDM) terão sua relação analisada neste trabalho.

\section{MÉTODO DE PESQUISA}

Este estudo busca definir o grau de transparência, por meio da EBT, dos portais eletrônicos dos 25 municípios integrantes do COREDE Missões/RS. No Quadro 1, são apresentados os indicadores socioeconômicos avaliados, as respectivas bases de dados, as hipóteses estatísticas e a sustentação teórica, a fim de verificar as relações existentes com a transparência municipal mensurada.

Quadro 1 - Indicadores e hipóteses estatísticas com respectiva sustentação teórica

\begin{tabular}{|c|c|c|}
\hline $\begin{array}{l}\text { Indicador (base } \\
\text { de dados) }\end{array}$ & Hipótese estatística & Sustentação teórica \\
\hline $\begin{array}{l}\text { População } \\
\text { (IBGE, 2010) }\end{array}$ & $\begin{array}{l}\text { H1. Municípios mais populosos } \\
\text { tendem a ser mais transparen- } \\
\text { tes na sua gestão. }\end{array}$ & $\begin{array}{l}\text { Cruz, Silva e Santos. (2010), Ma- } \\
\text { chado (2013), Marques (2014), Ave- } \\
\text { lino et al. (2014) e Rossoni e Beiruth } \\
\text { (2016). }\end{array}$ \\
\hline $\begin{array}{c}\text { Receita Total } \\
\text { Arrecadada } \\
\text { (SICONFI, 2018) }\end{array}$ & $\begin{array}{l}\text { H2. Prefeituras cujo poder } \\
\text { de arrecadação de receitas é } \\
\text { maior apresentam níveis de } \\
\text { evidenciação na gestão pública } \\
\text { mais elevados. }\end{array}$ & $\begin{array}{l}\text { Cruz, Silva e Santos (2010), Cruz } \\
\text { et al. (2012), Ribeiro, Zuccolotto } \\
\text { (2012), Marques (2014), Avelino } \\
\text { et al. (2014), Possamai, Schindler } \\
\text { (2017) e Bernardo, Reis e Sediyama } \\
\text { (2017). }\end{array}$ \\
\hline $\begin{array}{l}\text { PIB per capita } \\
\text { (IBGE, 2010) }\end{array}$ & $\begin{array}{l}\text { H3. Municípios com maior PIB } \\
\text { per capita apresentam melho- } \\
\text { res níveis de evidenciação da } \\
\text { gestão municipal. }\end{array}$ & $\begin{array}{l}\text { Machado (2013), Cruz et al. (2012), } \\
\text { Possamai e Schindler (2017). }\end{array}$ \\
\hline $\begin{array}{c}\text { IDH-M } \\
\text { (PNUD, 2010) }\end{array}$ & $\begin{array}{l}\text { H4. Municípios que apresentam } \\
\text { um maior nível IDH-M possuem } \\
\text { maior transparência eletrônica } \\
\text { na sua gestão. }\end{array}$ & $\begin{array}{l}\text { Cruz, Silva e Santos (2010) e Cruz } \\
\text { et al. (2012). }\end{array}$ \\
\hline $\begin{array}{c}\text { Taxa de } \\
\text { alfabetização (FEE } \\
\text { Dados, 2010) }\end{array}$ & $\begin{array}{l}\text { H5. Quanto maior a taxa de al- } \\
\text { fabetização, maior é o nível de } \\
\text { transparência. }\end{array}$ & $\begin{array}{l}\text { Cruz, Silva e Santos (2010), Macha- } \\
\text { do (2013), Marques (2014), Avelino } \\
\text { et al. (2014) e Rossoni e Beiruth } \\
(2016) \text {. }\end{array}$ \\
\hline $\begin{array}{c}\text { IFDM } \\
\text { (Site IFDM, 2013) }\end{array}$ & $\begin{array}{l}\text { H6. Estima-se que o IFDM seja } \\
\text { um fator que se relaciona com o } \\
\text { nível de transparência das ges- } \\
\text { tões públicas municipais. }\end{array}$ & $\begin{array}{l}\text { Cruz et al. (2012), Machado (2013), } \\
\text { De Queiroz et al. (2013), Avelino et } \\
\text { al. (2014), Rossoni e Beiruth (2016) } \\
\text { e Brocco et al. (2018). }\end{array}$ \\
\hline
\end{tabular}

Fonte: Elaborado pelos autores (2020). 
A EBT é composta por 12 quesitos divididos entre "Regulamentação da LAl" e "Transparência Passiva", este último está voltado para assuntos das principais áreas sociais: saúde, educação e assistência social, bem como para a regulamentação do acesso à informação pelo ente avaliado (prefeitura municipal). A metodologia da EBT permite a divulgação de uma métrica, com pontuação entre 0 e 10, sendo que $25 \%$ dessa pontuação informa sobre a regulamentação do acesso à informação e $75 \%$ sobre a existência e funcionamento do Serviço de Informação ao Cidadão (SIC). O checklist possui um preenchimento binário, sendo possível somente respostas "SIM" ou "NÃO" para cada quesito. A exceção ocorre quando não são encontrados os portais eletrônicos ou quando estes estiverem fora do ar, neste caso podendo ser utilizado os termos "Não Localizado" ou "Site Fora do Ar" (Brasil, 2017).

No checklist da EBT (disponível no site da CGU), é possível visualizar que todos os itens têm uma pontuação correspondente com base no cumprimento ou não do requisito das transparências ativa e passiva. Este é somado ao cálculo da nota com um total máximo de 3.600 pontos. Como regra geral, a resposta "SIM" gera uma pontuação máxima para cada quesito e a resposta "NÃO" gera uma pontuação zero.

A partir disso, a nota final obtida para cada município depende de quantos requisitos solicitados no checklist são atendidos. A pontuação varia de 0 a 3.600 pontos e então é convertida de 0 a 10 pontos para uma melhor compreensão da sociedade através da seguinte fórmula: Nota $=($ Pontuação atingida / 3600 $){ }^{*} 10$ (Brasil, 2017). A nota final permite que uma comparação seja feita entre os municípios estudados devido ao nível de transparência passiva que é ofertado aos cidadãos, bem como a criação de um ranking dos entes avaliados.

Os portais eletrônicos dos 25 municípios foram avaliados de acordo com a EBT, ou seja, em relação ao cumprimento da LAI e da transparência passiva através da existência e funcionamento do SIC. Dando continuidade a pesquisa, quando encontrados o SIC nas homepages das prefeituras, foram feitos os pedidos de informação conforme o manual da EBT, abrangendo 4 diferentes perguntas acerca das áreas de saúde, educação, assistência social e regulamentação da LAI. Os portais eletrônicos dos municípios integrantes do COREDE Missões/RS foram observados e analisados no período de junho a julho de 2018.

Os dados coletados foram tabulados em planilhas do Microsoft Excel 2016, versão 2001. Para verificar se existe relação entre os indicadores selecionados e o nível de transparência, foi realizada a análise de Correlação de Spearman, que, segundo Field (2009), deve ser usada quando os dados violarem suposições paramétricas, como neste estudo, em que a amostra possui menos do que 30 casos 
(25 municípios que fazem parte do COREDE Missões/RS). Em complemento, Field (2009, p. 129) explica que "[...] como o coeficiente de correlação é uma medida padronizada de um efeito observado, ele é uma medida comumente usada do tamanho do efeito, e que valores de $\pm 0,1$ representam um efeito pequeno, $\pm 0,3$, um efeito médio e $\pm 0,5$, um efeito grande". Para a realização dessa análise, foi utilizado o software IBM SPSS Statistics Base 22.0, versão demonstrativa, livre para testes.

\section{APRESENTAÇÃO E DISCUSSÃO DOS RESULTADOS}

No período de análise, para preencher o checklist no que compete à transparência ativa, realizou-se o acesso aos portais eletrônicos das 25 prefeituras, conforme orientação da EBT. No que compete à transparência passiva, os pedidos de informação foram enviados, respeitando a exigência da LAI, cumprindo o prazo de espera de no mínimo 20 dias para a obtenção de respostas por parte das prefeituras, prazo esse que poderia ser prorrogado por mais 10 dias mediante as suas justificativas. Para todas as prefeituras este critério foi rigorosamente atendido. Alguns obstáculos foram encontrados na análise dos sites, bem como na realização dos pedidos de informação no Sistema Eletrônico de Informação ao Cidadão (e-SIC), que integra o Portal da Transparência das prefeituras.

No portal eletrônico dos municípios de Entre-ljuís, de São Pedro do Butiá e de Vitória das Missões foram realizadas tentativas diárias, do dia 11 de junho à 11 de julho de 2018. Durante esse período (30 dias), não foi possível concluir o cadastro do solicitante no site da prefeitura de Entre-ljuís, pois foi relatado que: "Ocorreu um erro na inclusão dos dados do Solicitante". Nos portais eletrônicos dos municípios de São Pedro do Butiá e de Vitória das Missões, os protocolos dos pedidos de informação não eram gerados, dificultando, portanto, o seu acompanhamento. A dificuldade encontrada no site de Guarani das Missões foi que ele não possuía e-SIC e/ou Ouvidoria, impossibilitando o envio das perguntas.

É importante frisar que os pedidos de informação foram enviados em nome de 4 pessoas diferentes, de acordo com o manual da Escala Brasil Transparente . Além disso, cabe ressaltar também que foi através de tais pedidos de informação que se pôde perceber a real efetivação do cumprimento da Lei de Acesso à Informação pelas prefeituras estudadas, no que se refere a transparência passiva. É perceptível, portanto, que não há um padrão nos portais eletrônicos das prefeituras para enviar os pedidos de informação. Pode-se notar este não cumprimento da lei no município de Entre-ljuís, pois no site da prefeitura é solicitado um cadastro para, então, ter acesso a página da solicitação do pedido. 
Ao investigarem o atendimento às exigências de transparência passiva pelas câmaras de municípios brasileiros, Raupp e Pinho (2016) constataram que, entre aquelas que responderam a solicitação do pedido de informação, muitas exigiram a identificação através de documentos pessoais para que as informações pudessem ser disponibilizadas. Comparando, portanto, os resultados encontrados por esses autores e o resultado encontrado no município de Entre-ljuís (cadastro solicitado na página da prefeitura), percebe-se que tais condutas acabam tornando possíveis as barreiras para acessar as informações desejadas.

Além disso, Raupp e Pinho (2016) questionam sobre os sites que têm a possibilidade de enviar as solicitações eletronicamente, mas mesmo assim o pedido não pode ser enviado, como no caso do município de Entre-ljuís e de Vitória das Missões. A questão que eles abordam é se os técnicos que estruturaram os sites fazem testes para comprovar que os formulários e as páginas funcionam, ou se são criados apenas para "cumprir" com a LAI.

Quando analisados os sites das prefeituras dos municípios do COREDE Missões/RS, ficou claro que para aqueles que cumprem com a legislação 12.527/2011 é necessário apenas nome, CPF e e-mail, e os que não cumprem requerem faixa etária, escolaridade, profissão, telefone, endereço e sexo, bem como o cadastro. Além desses obstáculos, alguns municípios não responderam aos pedidos de informação solicitados ou não foi possível entrar em contato com o ente público, conforme Quadro 2.

Quadro 2 - Obstáculos encontrados em alguns municípios do COREDE Missões/RS

\begin{tabular}{|c|c|}
\hline Município & $\begin{array}{l}\text { Pedidos não respondidos/Impossibilidade de contato com } \\
\text { a prefeitura através do site }\end{array}$ \\
\hline Caibaté & Educação, Assistência Social e Regulamentação da LAI. \\
\hline Entre-ljuís & $\begin{array}{l}\text { Não foi possível entrar em contato com a prefeitura através do } \\
\text { e-SIC, Ouvidoria ou Fale Conosco. }\end{array}$ \\
\hline Garruchos & Não respondeu nenhum dos pedidos. \\
\hline Giruá & Educação. \\
\hline Guarani das Missões & $\begin{array}{l}\text { Não foi possível entrar em contato com a prefeitura através do } \\
\text { e-SIC, Ouvidoria ou Fale Conosco. }\end{array}$ \\
\hline Pirapó & Não respondeu nenhum dos pedidos. \\
\hline Rolador & Não respondeu nenhum dos pedidos. \\
\hline Salvador das Missões & Não respondeu nenhum dos pedidos. \\
\hline São Miguel das Missões & Não respondeu nenhum dos pedidos. \\
\hline São Pedro do Butiá & $\begin{array}{l}\text { Não foi possível entrar em contato com a prefeitura através do } \\
\text { e-SIC, Ouvidoria ou Fale Conosco. }\end{array}$ \\
\hline Ubiretama & $\begin{array}{l}\text { Não foi possível entrar em contato com a prefeitura através do } \\
\text { e-SIC, Ouvidoria ou Fale Conosco. }\end{array}$ \\
\hline Vitória das Missões & $\begin{array}{l}\text { Não foi possível entrar em contato com a prefeitura através do } \\
\text { e-SIC, Ouvidoria ou Fale Conosco. }\end{array}$ \\
\hline
\end{tabular}


Os obstáculos encontrados e os pedidos de informação não atendidos mostram que, em alguns municípios do COREDE Missões/RS, os cidadãos são impossibilitados de obter conhecimento sobre os atos praticados por parte da administração pública. Cruz, Silva e Santos (2010) afirmam que a transparência das informações deve ocorrer em todas as atividades praticadas pelos gestores, de forma que os cidadãos obtenham acesso a todas as informações (exceto as sigilosas) e, principalmente, consigam compreender as informações que estão sendo divulgadas.

A LAI surgiu para garantir aos cidadãos o acesso às informações, a fim de proporcionar à sociedade o engajamento dos governantes na prestação de contas, bem como a responsabilização por seus atos, consequentemente, fomentando a accountability (Lacerda, 2016). O Art. $42^{\circ}$ dessa lei, que foi instituída no ano de 2011, regulamentou que o Poder Executivo teria o prazo de 180 dias a partir da data da publicação para regulamentar a lei de cada município (Brasil, 2011).

De acordo com os achados nesta pesquisa, 12 (48\%) dos municípios estudados regulamentaram a LAI, quais sejam: Caibaté, Cerro Largo, Eugênio de Castro, Giruá, Porto Xavier, Rolador, Roque Gonzales, Santo Antônio das Missões, São Luiz Gonzaga, São Nicolau, São Paulo das Missões, e São Pedro do Butiá. Vale a pena ressaltar que, apesar dos 12 municípios terem cumprido com a LAI e criado sua própria legislação tomando como base a lei federal, todos excederam o prazo de 180 dias.

Após a posterior análise da regulamentação da LAI, que possui peso de $25 \%$ no checklist da EBT, os pedidos de acesso à informação, que correspondem a $75 \%$, também foram analisados para verificar a transparência passiva dos municípios. A partir desses pesos, uma nota geral foi atribuída a cada município, permitindo, portanto, a efetivação de um ranking, conforme a Tabela 1.

Tabela 1 - Nota e Ranking EBT dos municípios do COREDE Missões/RS

\begin{tabular}{ccc|ccc}
\hline Município & $\begin{array}{c}\text { Nota } \\
\text { EBT }\end{array}$ & $\begin{array}{c}\text { Ranking } \\
\text { na EBT }\end{array}$ & Município & $\begin{array}{c}\text { Nota } \\
\text { EBT }\end{array}$ & $\begin{array}{c}\text { Ranking } \\
\text { na EBT }\end{array}$ \\
\hline Cerro Largo & 10,00 & $1^{\circ}$ & Sete de Setembro & 6,25 & $10^{\circ}$ \\
\hline $\begin{array}{c}\text { Santo Antônio das } \\
\text { Missões }\end{array}$ & 10,00 & $1^{\circ}$ & Caibaté & 5,83 & $11^{\circ}$ \\
\hline São Paulo das Missões & 10,00 & $1^{\circ}$ & Rolador & 5,28 & $12^{\circ}$ \\
\hline São Luiz Gonzaga & 9,72 & $2^{\circ}$ & São Pedro do Butiá & 3,33 & $13^{\circ}$ \\
\hline Eugênio de Castro & 9,72 & $2^{\circ}$ & Garruchos & 3,06 & $14^{\circ}$ \\
\hline São Nicolau & 9,58 & $3^{\circ}$ & Pirapó & 3,06 & $14^{\circ}$ \\
\hline Porto Xavier & 9,17 & $4^{\circ}$ & São Miguel das & 3,06 & $14^{\circ}$ \\
\hline Roque Gonzales & 8,61 & $5^{\circ}$ & Vitória das Missões & 2,22 & $15^{\circ}$ \\
\hline Giruá & 8,47 & $6^{\circ}$ & Salvador das Missões & 1,39 & $16^{\circ}$ \\
\hline
\end{tabular}


A TRANSPARÊNCIA PÚBLICA NOS MUNICÍPIOS INTEGRANTES DO COREDE/MISSÕES-RS E SUA RELAÇÃO COM OS INDICADORES SOCIOECONÔMICOS

\begin{tabular}{ccc|ccc}
\hline Mato Queimado & 7,78 & $7^{\circ}$ & Ubiretama & 1,39 & $16^{\circ}$ \\
\hline Santo Ângelo & 7,78 & $7^{\circ}$ & Entre-ljuís & 0,02 & $17^{\circ}$ \\
\hline $\begin{array}{c}\text { Dezesseis de } \\
\text { Novembro }\end{array}$ & 7,50 & $8^{\circ}$ & Guarani das Missões & 0,00 & $18^{\circ}$ \\
\hline Bossoroca & 6,67 & $9^{\circ}$ & & & \\
\hline
\end{tabular}

Fonte: Dados da pesquisa, 2020.

Nota: o ranking na EBT não perfaz 25 posições em decorrência de ter havido municípios com a mesma nota, logo considerou-se com a mesma colocação, classificando-os em ordem alfabética.

Conforme apresentado na Tabela 1, os municípios de Cerro Largo, de Santo Antônio das Missões e de São Paulo das Missões atingiram a pontuação máxima, pois atenderam a todos os quesitos presentes na EBT. Os municípios de São Luiz Gonzaga e de Eugênio de Castro não atingiram a pontuação máxima porque apenas um quesito não foi atendido: a indicação de endereço do SIC físico e a indicação dos horários de funcionamento, respectivamente.

Os municípios de São Nicolau e Porto Xavier obtiveram uma nota próxima da pontuação máxima, porém o município de São Nicolau não cumpriu com o prazo dos 20 dias para a resposta da solicitação do pedido referente à Assistência Social. O município de Porto Xavier não atendeu ao pedido de informação sobre a regulamentação da LAI, o qual solicitava que a norma fosse enviada juntamente com a resposta.

Os 4 últimos municípios do ranking se destacaram de forma negativa. No caso do município de Salvador das Missões, o ente cumpriu apenas com o quesito de enviar pedidos na forma eletrônica, por meio do e-SIC. No município de Ubiretama, o único quesito atendido também foi o envio dos pedidos na forma eletrônica, porém foram feitos através da Ouvidoria. É importante ressaltar que, entre os 25 municípios investigados, o único que possui a Ouvidoria como meio de comunicação entre cidadão e gestão pública é o município de Ubiretama, os demais têm o e-SIC como meio de comunicação.

No caso de Entre-ljuís, além do cadastro que é exigido para conseguir realizar o pedido de acesso à informação, como citado anteriormente, o único quesito que o município cumpre no site é a alternativa de enviar as solicitações ao SIC de forma eletrônica. Pode-se comparar tais resultados com os achados da pesquisa de Raupp e Pinho (2011), nas câmaras municipais de municípios com população superior a 50 mil habitantes do estado de Santa Catarina, os quais observaram que a participação e interação dos cidadãos mostrou-se bastante frágil, pois os portais possuem uma baixa capacidade de contribuir para a construção da 
accountability.

Michener, Moncau e Velasco (2015) afirmam que é fundamental que o processo de envio dos pedidos e o recebimento de respostas por parte dos entes públicos seja o mais simples possível, tornando o processo descomplicado e eficiente. Afirmam ainda que os sites deveriam possuir uma ferramenta de busca para que o cidadão possa identificar respostas a pedidos similares.

Por fim, em último lugar, encontra-se o município de Guarani das Missões, devido ao fato de o ente não ter cumprido nenhum dos requisitos exigidos pela LAI, ou seja, na página eletrônica do município não foi possível localizar o e-SIC, Ouvidoria ou até mesmo o Fale Conosco. Além disso, a Lei 12.527/11 não foi localizada no site e não há indicação de um SIC físico, consequentemente, resultando em pontuação nula.

Ao analisar a transparência ativa e passiva dos municípios do COREDE Missões/RS, o que se percebe é que a falta de transparência - principalmente passiva - em alguns municípios impossibilita a essência da Lei de Acesso à Informação, que trata justamente sobre a regulamentação da transparência passiva e classificação de documentos no Brasil. Logo, é perceptível que nos municípios que possuem em seus portais o e-SIC, mas não respondem as solicitações dos cidadãos, foram criados somente como forma de atender à legislação, servindo como "murais eletrônicos" (Raupp \& Pinho, 2011) e não como espaço para promoção da transparência pública.

A fim de identificar a possível relação entre a transparência e os indicadores, apresenta-se na Tabela 2 a descrição dos indicadores avaliados. A média da população dos municípios do COREDE Missões/RS é de 9.878 habitantes e o desvio-padrão de 15.468, sendo o menor município o de Mato Queimado, com 1.799 habitantes e o maior município o de Santo Ângelo, com 76.275 habitantes. O desvio-padrão elevado se deu pelas diferenças entre os municípios com maior e menor população. Em se tratando da receita total arrecadada, que obteve como média $\mathrm{R} \$ 31.486 .698,97$, também se destacam estes dois municípios, pois o valor mínimo de receita total arrecadada foi de Mato Queimado com R\$12.332.152,57, e máxima de $\mathrm{R} \$ 166.773 .996,03$, correspondente ao município de Santo Ângelo. 
A TRANSPARÊNCIA PÚBLICA NOS MUNICÍPIOS INTEGRANTES DO COREDE/MISSÕES-RS E SUA RELAÇÃO COM OS INDICADORES SOCIOECONÔMICOS

Tabela 2 - Estatística descritiva dos indicadores analisados

\begin{tabular}{cccccccc}
\hline & População & $\begin{array}{c}\text { Receita total ar- } \\
\text { recadada }\end{array}$ & PIB & IDH-M & $\begin{array}{c}\text { Taxa de Al- } \\
\text { fabetização }\end{array}$ & IFDM & $\begin{array}{c}\text { Nota no } \\
\text { ranking }\end{array}$ \\
\hline Média & $9.878,36$ & $31.486 .698,97$ & $29.274,68$ & 0,7 & 92,45 & 0,7 & 6,04 \\
\hline $\begin{array}{l}\text { Desvio- } \\
\text {-padrão }\end{array}$ & $15.467,99$ & $32.686 .563,57$ & $13.683,99$ & 0,04 & 3,27 & 0,05 & 3,33 \\
\hline Mínimo & $1.799,00$ & $12.332 .152,57$ & $12.262,89$ & 0,65 & 86,27 & 0,58 & 0 \\
\hline Máximo & $76.275,00$ & $166.773 .996,03$ & $78.568,83$ & 0,77 & 98,13 & 0,79 & 10 \\
\hline
\end{tabular}

Fonte: Dados da pesquisa (2020).

Já em relação ao indicador PIB per capita, a média foi de $\mathrm{R} \$ 29.274,68$. O maior valor encontrado para este indicador foi de $\mathrm{R} \$ 78.568,83$, no município de Roque Gonzales e o menor valor foi de $\mathrm{R} \$ 12.262,89$, correspondente ao município de Dezesseis de Novembro.

A média encontrada no IDH-M foi de 0,70 , considerada alta conforme os critérios do PNUD. Ressalta-se que, quanto mais próximo de 1, maior o desenvolvimento humano (Pnud, 2010). Sendo assim, o município com maior índice foi Santo Ângelo, com 0,77, e São Nicolau foi o município que apresentou o menor índice, com 0,65.

O indicador taxa de analfabetismo foi convertido em taxa de alfabetização. Para isso, foram utilizados os dados de taxa de analfabetismo de pessoas de 15 anos ou mais, do ano de 2010, encontrados no site da Fundação de Economia e Estatística (FEE Dados, 2010), responsável por reunir informações de natureza socioeconômica dos municípios do Rio Grande do Sul. Ressalta-se que os dados da taxa de analfabetismo já estavam em porcentagem, portanto, foram subtraídos de $100 \%$ para chegar aos valores da taxa de alfabetização. A média da taxa de alfabetização dos municípios do COREDE Missões/RS foi de $92,45 \%$, enquanto a taxa de analfabetismo, no Brasil em 2015, divulgada pelo IBGE (2015) foi de $8 \%$, ou seja, fazendo a conversão, a taxa de alfabetização é de $92 \%$.

Dessa forma, é perceptível que os municípios do COREDE Missões/RS apresentam taxa de alfabetização acima da média nacional. Entre os municípios estudados, o que possui a menor taxa de alfabetização é o município de Pirapó, com $86,27 \%$, e Salvador das Missões é o município que possui o melhor resultado da amostra, com $98,13 \%$.

Quanto ao indicador IFDM, a média encontrada foi de 0,70 , considerado um desenvolvimento moderado pelo sistema FIRJAN. Vale ressaltar que a metodologia utilizada para o indicador IFDM (2013) é a mesma do indicador IFGF (2016), em se tratando da pontuação. Dessa forma, o município que apresentou menor 
índice foi Roque Gonzales, com 0,58 e, o maior índice encontrado foi do município de Salvador das Missões, com 0,79.

Além dos indicadores citados, a nota do ranking também foi analisada. Destaca-se que a média das notas dos municípios foi de 6,04, tendo como nota mínima o município de Guarani das Missões, com 0,00, e nota máxima os municípios de Cerro Largo, de Santo Antônio das Missões e de São Paulo das Missões.

Após a análise descritiva dos indicadores, buscou-se verificar a relação entre o nível de transparência dos municípios do COREDE Missões/RS e os indicadores socioeconômicos estudados. Para isso, foi utilizado o coeficiente de correlação de Spearman, que, segundo Field (2009), faz parte da estatística não-paramétrica, pois a amostra é composta por 25 municípios. A Tabela 3 apresenta os resultados encontrados para a correlação entre a nota média no ranking dos municípios estudados e os indicadores.

Tabela 3 - Resultado da correlação de Spearman aplicada à nota média no ranking dos municípios estudados e os indicadores

\begin{tabular}{ccccccc}
\hline $\begin{array}{c}\text { Nota no } \\
\text { ranking }\end{array}$ & População & $\begin{array}{c}\text { Receita total } \\
\text { arrecadada }\end{array}$ & $\begin{array}{c}\text { PIB per } \\
\text { capita }\end{array}$ & IDH-M & $\begin{array}{c}\text { Taxa de } \\
\text { Alfabetiza- } \\
\text { ção }\end{array}$ & IFDM \\
\hline $\begin{array}{c}\text { Coeficiente de } \\
\text { correlação }\end{array}$ & $0,402^{*}$ & $0,399^{*}$ & 0,004 & 0,166 & $-0,117$ & $-0,04$ \\
\hline $\begin{array}{c}\text { Sig. (2 extre- } \\
\text { mid.) }\end{array}$ & $\mathbf{0 , 0 4 7}$ & $\mathbf{0 , 0 4 8}$ & 0,983 & 0,429 & 0,577 & 0,865 \\
\hline $\mathrm{N}$ & 25 & 25 & 25 & 25 & 25 & 25 \\
\hline
\end{tabular}

Fonte: Dados da pesquisa, 2020.

Os únicos indicadores que possuem relação significativa foram população e receita total arrecadada, a um nível de 95\% de confiança (sig. <0,05), ambos apresentam um efeito médio de 0,402 e 0,399, respectivamente, de relação com a transparência (FIELD, 2009). Os estudos de Cruz, Silva e Santos (2010), de Cruz et al. (2012), de Ribeiro e Zuccolotto (2012), de Marques (2014), de Avelino et al. (2014), de Rossoni e Beiruth (2016) e de Possamai e Schindler (2017) assemeIham-se a esta pesquisa, uma vez que também encontraram relação significativa entre os indicadores.

Assim, entende-se que há relação entre o nível de transparência e o tamanho da população do município e a receita total por ele arrecadada. Dada a correlação positiva encontrada, presume-se que, os municípios maiores e com maior receita associam-se a um nível de transparência mais elevado. Uma possível explicação para esta associação pode estar no fato de municípios mais populosos 
e, consequentemente, com maior receita arrecadada, divulgar maior quantidade de informações em seus portais eletrônicos em razão da disponibilidade de recursos para o investimento na gestão da informação. Segundo Batista (2017), isso se dá pelo fato de que em municípios de pequeno porte com baixa capacidade de arrecadação, ou seja, com escassez de recursos financeiros e/ou humanos, a regulamentação da LAl é vista como uma necessidade de "segunda ordem", não sendo uma prioridade o seu cumprimento.

De forma geral, os resultados encontrados até aqui corroboram com o estudo de Silva et al. (2019), comprovando que em municípios de pequeno porte a transparência tende a ser menor do que em municípios de médio e grande porte. Nos municípios do COREDE Missões/RS, uma das explicações para a falta de transparência nos portais eletrônicos é o fato de que algumas gestões terceirizam seus portais, fornecendo, em muitos casos, o mesmo software de gestão pública para diversas cidades, além de alimentarem o sistema e liberarem acesso somente para as postagens com fins informativos. Essas questões mostram a falta de infraestrutura, de organização e de recursos humanos e financeiros desses municípios (Santos \& Visentini, 2018).

Além disso, estudos internacionais como de Muñoz, Bolívar e Hernández (2017) e de Tejedo-Romero e Araujo (2018) vão ao encontro deste estudo ao passo que também encontraram relação entre transparência pública e população. Os achados do estudo de Muñoz, Bolívar e Hernández (2017) mostram que a transparência municipal pode ser mais evidenciada em municípios mais populosos do que em municípios menos populosos, isto porque, segundo os autores, em municípios de grande porte os cidadãos possuem mais acesso à Internet e a gestão é pressionada por um maior número de pessoas.

Já o estudo de Tejedo-Romero e Araujo (2018) deixa evidente que, em comparação às cidades de pequeno e médio porte, cidades com mais habitantes têm a possibilidade de investir mais recursos financeiros e técnicos quando se trata da divulgação de informações, principalmente de cunho financeiro. Logo, municípios maiores estão mais propensos a divulgar maior quantidade de informações devido ao tamanho da população e à quantidade de recursos disponíveis, diferentemente da realidade encontrada nos municípios do COREDE Missões/RS.

Referente aos indicadores que não apresentaram relação significativa pode-se observar resultados semelhantes na literatura. Por exemplo, Marques (2014), Avelino et al. (2014) e Brocco et al. (2018) não verificaram relação entre a transparência e os indicadores PIB per capita, IDH-M e taxa de alfabetização. Já Ribeiro 
e Zuccolotto (2012) não encontraram significância estatística na relação entre o nível de transparência dos municípios e o IFDM.

\section{CONSIDERAÇÕES FINAIS}

O presente trabalho teve como objetivo mensurar o nível de transparência, por meio da EBT, nos portais eletrônicos das prefeituras que fazem parte do Conselho Regional de Desenvolvimento das Missões/RS. Para um melhor entendimento sobre este trabalho, bem como o tema abordado, primeiramente buscou-se explicar sobre a transparência na gestão pública e sua fundamental importância, pois quando há transparência, teoricamente, há o fomento do accountability exercido entre o Estado e o cidadão, dessa forma, estimulando a cidadania e a consciência ética na administração pública.

Para o alcance do objetivo proposto, mensurar o nível de transparência, através da EBT, nos portais eletrônicos das 25 prefeituras que fazem parte do Conselho Regional de Desenvolvimento das Missões/RS e verificar a sua relação com os indicadores socioeconômicos, obteve-se como resultados que os municípios investigados apresentam baixos níveis de transparência eletrônica, principalmente em se tratando da transparência passiva, apesar de 14 (56\%) dos municípios obterem notas acima de 6,00. Além disso, no ranking elaborado, 3 municípios (Cerro Largo, Santo Antônio das Missões e São Paulo das Missões) dos 25 investigados obtiveram nota máxima, enquanto o município de Guarani das Missões obteve pontuação nula, pelo fato de não cumprir com nenhum dos requisitos da LAI, bem como do checklist da EBT.

O trabalho também buscou analisar a possível relação entre os indicadores socioeconômicos (população, receita total arrecadada, PIB per capita, IDH-M, taxa de alfabetização, IFDM) e o nível de transparência mensurado pela EBT dos municípios integrantes do COREDE Missões/RS, conforme exposto anteriormente. Através dos resultados encontrados pela análise da correlação de Spearman, pode-se aceitar as hipóteses de existência de relação entre o nível de transparência do município e os indicadores populacionais (tamanho da população) e de receita total arrecadada, corroborando alguns estudos anteriores. Presume-se que este resultado reflita que municípios com maior população e receita arrecadada dispõem de mais recursos para investir em sistemas de gestão da informação e de ferramentas de transparência na internet.

Os sites foram observados e analisados durante o período de um mês (ju- 
nho de 2018 a julho de 2018). Juntamente com a análise dos sites, foram enviadas as solicitações de 4 perguntas sobre os seguintes temas, conforme manual da EBT: saúde, educação, assistência social e regulamentação da LAI.

Ressalta-se que uma das limitações desta pesquisa foi que alguns municípios dificultam o acesso à informação para os cidadãos em seus portais eletrônicos, como os municípios de Entre-ljuís, de Guarani das Missões, de São Pedro do Butiá, de Ubiretama e de Vitória das Missões. Além disso, percebeu-se ao longo da análise dos 25 portais eletrônicos que não há uma padronização dos conteúdos disponibilizados.

Os achados desta pesquisa indicam a necessidade de uma visão mais crítica dos cidadãos com a situação de seu município quando se trata da transparência. Isso porque, a realidade dos municípios em análise permite inferir que há uma longa trajetória a ser percorrida para que a transparência seja tratada como uma questão imprescindível na gestão pública. Portanto, os resultados deste estudo corroboram com Batista (2017, p. 72) na ideia de que "os governos que não regulamentam a LAI podem ser exatamente aqueles que mais precisem de transparência". Ainda que $48 \%$ dos municípios estudados tenham ratificado esta legislação, não podem ser considerados transparentes em sua totalidade e um dos motivos é por impossibilitarem a interação entre os cidadãos e a gestão pública municipal.

A partir disso, percebe-se que apesar de haver gestões que cumprem com essa legislação, alguns portais foram elaborados apenas por obrigação jurídica e não pela vontade da administração municipal disponibilizar o acesso à informação aos cidadãos, dificultando o exercício da cidadania e, consequentemente, o controle social. Além disso, resultados como estes alertam para a necessidade de maior participação, colaboração e fiscalização da população no que se refere à gestão de seus municípios, pois assim é possível obter informações quanto aos rumos das políticas públicas, bem como exigir uma crescente melhoria e ações transparentes da gestão municipal.

Além disso, a limitação encontrada em se tratando da transparência municipal mensurada pela EBT em relação aos indicadores socioeconômicos mencionados, é que muitos dados não são tão recentes, por exemplo, os dados obtidos do site do IBGE (2010) quanto ao indicador população, do ano de 2010; a taxa de alfabetização do site FEE Dados (2010), também do ano de 2010; e o IFDM (2013), do ano de 2013.

Para estudos futuros, sugere-se a realização de uma amostragem probabilística dos municípios gaúchos, a fim de verificar a situação da transparência a 
nível estadual. Estudos de nível macro, considerando o cenário nacional também seriam interessantes, tendo em vista que a última avaliação da EBT, realizada pela CGU em 2016, avaliou 2.328 municípios, podendo esta amostra ser ampliada para uma maior compreensão do contexto, além de realizar a comparação entre os resultados por porte dos municípios ou regiões do país, por exemplo. Logo, recomenda-se para estudos futuros uma amostra mais significativa a nível estadual ou nacional.

Espera-se que, com este estudo, os gestores públicos possam identificar nos municípios investigados os principais problemas relacionados à divulgação de informações aos cidadãos. Para que isso ocorra, como conclusões de cunho prático, sugere-se que tais governantes se atentem à LAI, atendendo a todos os quesitos necessários através de uma melhoria dos portais eletrônicos, bem como a sua padronização.

1 O IFDM é um indicador de estudo para verificar o desenvolvimento dos municípios brasileiros em três áreas de atuação: emprego e renda, educação e saúde. Este índice varia de 0 (mínimo) a 1 ponto (máximo) para classificar o nível de cada localidade em quatro categorias: baixo (de 0 a 0,4$)$, regular $(0,4$ a 0,6$)$, moderado (de 0,6 a 0,8$)$ e alto $(0,8$ a 1) desenvolvimento, ou seja, quanto mais próximo de 1 , maior o desenvolvimento da localidade (IFDM, 2013).

${ }^{2} \mathrm{O}$ IFGF é um indicador de controle social que visa estimular a cultura da responsabilidade administrativa, proporcionando uma maior excelência da gestão fiscal dos municípios, bem como o aperfeiçoamento das decisões dos gestores públicos em se tratando da alocação dos recursos. Este índice tem uma pontuação que varia entre 0 e 1 , sendo que quanto mais próximo de 1 melhor a gestão fiscal do município (IFGF, 2016).

\section{REFERÊNCIAS}

Avelino, B. C., et al. (2011). Índice de disclosure nos Estados Brasileiros: Uma abordagem da Teoria da Divulgação. In $8^{\circ}$ Congresso USP de Iniciação Científica e Contabilidade, São Paulo, SP.

Avelino, B. C., et al. (2014). Características explicativas do nível de disclosure voluntário de municípios do estado de Minas Gerais. RACE-Revista de Administração, Contabilidade e Economia, 13(2), 571-608.

Bairral, M. A. da C., Silva, A. H. C., \& Alves, F. J. dos S. (2015). Transparência no setor público: uma análise dos relatórios de gestão anuais de entidades públicas federais no ano de 2010. Revista de Administração Pública-RAP, 49(3), 643-675.

Batista, M. (2017). A difusão da Lei de Acesso à Informação nos municípios brasileiros: fatores internos e externos. Cadernos Enap, 53, 01-84.

Bernardo, J. S., Reis, A. de O., \& Sediyama, G. A. S. (2017). Características explicativas do nível de transparência na administração pública municipal. Revista Ciências Administrativas, 23(2), 277-292. 
Bertê, A. M. de A., et al. (2015). Perfil Socioeconômico - COREDE Missões. Governo do Estado do Rio Grande do Sul. Secretaria do Planejamento, Mobilidade e Desenvolvimento Regional. Porto Alegre.

Brasil. (1988). Constituição da República Federativa do Brasil: promulgada em 5 de outubro de 1988.

Brasil. (2000). Lei de Responsabilidade Fiscal. Lei Complementar $n^{\circ} 101$, de 4 de Maio de 2000. Presidência da República. Casa Civil. Subchefia para Assuntos Jurídicos. Brasília, 2000.

Brasil. (2009). Lei Complementar $n^{\circ}$ 131, de 27 de maio de 2009. Presidência da República. Casa Civil. Subchefia para Assuntos Jurídicos. Brasília, DF.

Brasil. (2011). Lei n 12.527, de 18 de novembro de 2011. LAl: A Lei de Acesso à Informação. Presidência da República. Casa Civil. Subchefia para Assuntos Jurídicos. Brasília, DF.

Brasil. (2017). Controladoria-Geral da União (CGU). Escala Brasil Transparente. Recuperado de http://www.cgu.gov.br/assuntos/transparencia-publica/escala-brasil-transparente. Acesso em 20 mar. 2018.

Brocco, C. et al. (2018). Transparência da gestão pública municipal: Fatores explicativos do nível e transparência dos municípios de médio e grande porte do rio grande do sul. Revista Ambiente Contábil, 10 (1), 139-159.

Cruz, C. F., Silva, L. M., \& Santos, R. (2010). Transparência da gestão fiscal: um estudo a partir dos portais eletrônicos dos maiores municípios do Estado do Rio de Janeiro. Contabilidade, Gestão e Governança, 12(3), 102-115.

Cruz, C. F, et al. (2012). Transparência da gestão pública municipal: um estudo a partir dos portais eletrônicos dos maiores municípios brasileiros. Revista de Administração Pública, 46(1), 153-176.

De Oliveira, A. \& Santos, N. (2017). Transparência passiva nos pequenos municípios brasileiros. In Congresso da Associação Nacional de Programas de Pós-Graduação em Ciências Contábeis, 11., Belo Horizonte, BH.

Fundação de Economia e Estatística. (2010). COREDE Missões. Recuperado de https://www.fee.rs.gov.br/perfil-socioeconomico/coredes/. Acesso em 10 mar. 2018.

Field, A. (2009). Descobrindo a estatística usando o SPSS-2. 2. Porto Alegre: Artmed.

IBGE. (2010). Instituto Brasileiro de Geografia e Estatística. IBGE Cidades. Recuperado de https://cidades.ibge.gov.br/. Acesso em 05 abr. 2018.

IBGE. (2015). Instituto Brasileiro de Geografia e Estatística. Brasil em Síntese. 
Recuperado de https://brasilemsintese.ibge.gov.br/educacao/taxade-analfabetismo-das-pessoas-de-15-anos-ou-mais.html. Acesso em 05 abr. 2018. IFDM. (2013). Índice Firjan de Desenvolvimento Municipal. Leitura do IFDM. Recuperado de http://www.firjan.com.br/ifdm/. Acesso em 05 abr. 2018.

IFGF. (2016). Índice Firjan de Gestão Fiscal. Metodologia. Recuperado de https:// www.firjan.com.br/ifgf/metodologia/. Acesso em 05 abr. 2018.

Lacerda, S. M. de P. (2016). Governo aberto, transparência e governo eletrônico nas câmaras municipais paraibanas: um estudo multicaso. 128 f. (Dissertação de Mestrado), Universidade Federal da Paraíba, João Pessoa.

Machado, V. N. (2013). Fatores explicativos do nível de evidenciação nas páginas eletrônicas de municípios do sul do Brasil. 95 f. (Dissertação de Mestrado), Unisinos, São Leopoldo.

Marques, S. B. S. da S. (2014). Transparência nos pequenos municípios do Rio Grande do Sul: um estudo sobre a divulgação de indicadores da LRF e da LAI. 85 f. (Dissertação de Mestrado), Universidade do Vale do Rio dos Sinos, São Leopoldo.

Michener, G., Moncau, L. F., \& Velasco, R. B. (2015). Estado brasileiro e transparência avaliando a aplicação da Lei de Acesso à Informação: relatório técnico. Rio de Janeiro: FGV.

Muñoz, L. A., Bolívar, M. P. R. \& Hernández, A. M. L. (2017). Transparency in Governments: A Meta-Analytic Review of Incentives for Digital Versus Hard-Copy Public Financial Disclosures. American Review of Public Administration, 47(5), 550-573.

Programa das Nações Unidas para o Desenvolvimento - PNUD. (2010). Atlas do Desenvolvimento Humano no Brasil. Recuperado de http://www.br.undp.org/ content/brazil/pt/home/. Acesso em07 mai. 2018.

Possamai, A. J. \& Schindler, E. (2017). Transparência e Lei de Acesso à Informação (LAI) nos municípios gaúchos: fatores associados. Indicadores Econômicos FEE, 45(1), 71-86.

Queiroz, D. B. de, et al. (2013). Transparência dos municípios do Rio Grande do Norte: avaliação da relação entre o nível de disclosure, tamanho e características socioeconômicas. Revista Evidenciação Contábil \& Finanças, 1(2), 38-51.

Raupp, F. M. \& Pinho, J. A. G. de. (2011). Construindo a accountability em portais eletrônicos de câmaras municipais: um estudo de caso em Santa Catarina. Cadernos EBAPE, 9(1), 117-139. 
Raupp, F. M. \& Pinho, J. A. G. de. (2016). Review of passive transparency in Brazilian city councils. Revista de Administração, 51(3), 288-298.

Ribeiro, C. P. de P. \& Zuccolotto, R. (2012). Fatores determinantes da transparência na gestão pública dos municípios brasileiros. In Anais do Encontro de Administração Pública e Governo.

Rossoni, F. V. \& Beiruth, A. X. (2016). Transparência na Gestão Pública Municipal: Análise nos Sites das Prefeituras do Estado do Espírito Santo. Revista de Auditoria, Governança e Contabilidade-RAGC, 4(17), 01-16.

Santos, M. dos. (2017). Transparência na gestão pública Municipal nos Municípios que integram o Conselho Regional de Desenvolvimento das Missões/RS (Dissertação de Mestrado), Universidade Federal da Fronteira Sul, Cerro Largo.

Santos, M. dos. \& Visentini, M. S. (2018). Elaboração de um ranking da transparência e compreensão das práticas de gestão de municípios integrantes do COREDE Missões-RS. Administração Pública e Gestão Social, 10(4), 239-247.

SICONFI. (2018). Sistema de Informações Contábeis e Fiscais do Setor Público Brasileiro. Recuperado de https://siconfi.tesouro.gov.br/siconfi/pages/public/ declaracao/declaracao_list.jsf. Acesso em 12 abr. 2018.

Silva, C. L. da, Kumegawa, L. S. \& Vasconcelos, M. C. (2016). Governo eletrônico e transparência: comparativo Entre as Prefeituras Municipais de Curitiba, Belo Horizonte, Salvador e Porto Alegre. Perspectivas Contemporâneas, 11(2), 01-20.

Silva, M. C. et al. (2019). Determinantes da transparência municipal: uma análise empírica com municípios brasileiros. GCG Georgetown University - UNIVERSIA, 13(2), maio/ago.

Tejedo-Romero, F. \& Araujo, J. F. F. E. de. (2018). Transparencia en los municipios españoles: determinantes de la divulgación de información. Convergencia Revista De Ciencias Sociales, 25(78), 153-174.

\section{Agradecimentos:}

Os autores agradecem ao CNPq - Conselho Nacional de Desenvolvimento Científico e Tecnológico - pelo apoio financeiro ao projeto de processo $\mathrm{n}^{\circ}$ 405563/2016-7. 